\title{
Pengaruh Pijat Bayi yang Dilakukan oleh Ibu terhadap Tumbuh-Kembang dan Tidur Bayi di Kabupaten Klaten
}

\author{
Paryono $^{1 *}$, Ari Kurniarum ${ }^{2}$ \\ ${ }^{1,2}$ Poltekkes Kemenkes Surakarta Jurusan Kebidanan \\ *Email : pparyono2@gmail.com
}

\begin{abstract}
Background: Optimal growth and development of babies can be done through stimulation of the touch by containing massage. Babies who are massaged sleep more and compile waking up fresher. In Klaten District, parents ask for masseur services because their children are fussy and have trouble sleeping. No less than 30 babies every day who come in one massage place, even on holidays more than 60 babies who come. If you can do the massage yourself, you will be able to save money and get closer to the relationship between mother and baby, including other developments and developments, and help the baby's development. Purpose this study is analyze the effect of infant massage conducted by the mother on the growth and development of infants in Klaten Regency, it can be seen the growth and development of infant sleep. Methods: The research method is quasi-experimental with control. The study was conducted for 6 months, the intervention for 1 month consisted of training in infant massage in the group of mothers who had babies and conditioning other groups as a control group (not suitable for training). The group treated massage their babies every week for 1 month, while the other group (control) did not do massage. Data collected includes body, body length, the ability of motion received by the baby and the quality of sleep performed before and after massage in the control groups, as well as in the control groups at the time performed for 1 month. The research location is in Klaten Regency with a sample of the area in the working area of Trucuk and Central Klaten Puskesmas. Data analysis was carried out for 1 month to test hypotheses using the paired " $t$ " test to measure body weight, body length and sleep quality before and then get a good massage in the treated group with good control, through the unpaired " $t$ " test to measure the babies given massage compared to babies who are not massaged. Results: Tests of growth and development of babies and sleep between before and after the baby was massage by the results obtained with $p<0.05$ and in infants who were massaged by babies who were massaged obtained with $p<0.05$. Conclusion: Infant massage is provided by the mother for baby's growth and development and sleep in Klaten Regency.
\end{abstract}

Keywords: Baby Massage, Growth and Development, Baby Sleep

\section{PENDAHULUAN}

Setiap orang tua mendambakan anak tumbuh dan berkembang dengan baik. Pertumbuhan dan perkembangan anak mencakup 2 kejadian yang berbeda yaitu tumbuh sebagai bagian dari fisik dan berkembang merupakan bagian dari kematangan otak. Kedua proses ini berjalan secara alamiah (Soetjiningsih dan Ranuh, 2014).

Pada masa bayi pertumbuhan dan perkembangan terjadi secara cepat. Pertambahan berat badan rata rata setiap bulan $0,7-0,9 \mathrm{~kg}$ dan panjang badan 2,5- 4,0cm (Shelov, 2005). Pada tiga bulan pertama, anak berusahan mengelola koordinasi bola mata untuk mengikuti obyek, membedakan benda atau orang tersenyum dan bersuara.

Pada posisi telungkup anak berusaha mengangkat kepala, ketika telentang lebih sering menolehkan kepala ke samping. Pada umur enam bulan, anak mulai bergerak memutar posisi telungkup guna menjangkau benda. Pada usia Sembilan bulan, anak bergerak merayap atau merangkak dan mampu duduk sendiri tanpa bantuan (Susilaningrum, 2013). 
Peran orang tua adalah memberikan rangsang taktil agar terjadi koordinasi reflex dan gerak motorik, serta bayi responsif terhadap lingkungan. Stimulus yang baik dan diberikan sejak dini akan menjadikan bayi mempunyai kemampuan mengembangkan proses bicaranya sebagai respon otak yang bertanggung jawab dalam kemampuan bahasa. (Chamidah, 2009).

Pemberdayaan ibu agar dapat melakukan pemijatan pada bayinya merupakan salah satu cara yang aman dan murah untuk memberikan rangsangan agar bayi dapat tumbuh-kembang dan tidur dengan nyenyak secara optimal. Pijat sebagai terapi sentuh merupakan seni perawatan kesehatan dan penyembuhan yang menjadi tradisi turun temurun dan kearifan budaya lokal karena banyak dilakukan oleh masyarakat khususnya Jawa.

Sering ditemukan orang tua yang membawa anaknya ke tukang pijat atau praktik pijat bayi di Kabupaten Klaten, tak kurang dari 30 bayi yang datang di salah satu tempat pijat bayi setiap hari, bahkan pada hari-hari libur lebih dari 60 bayi yang datang. Dari wawancara kepada ibu ibu yang membawa bayinya untuk dipijat mengatakan setelah dipijat bayi tidak rewel, makan dan minumnya banyak dan lebih segar. Tujuan dari penelitian ini yaitu untuk mengetahui pengaruh pijat bayi yang dilakukan oleh ibu terhadap tumbuh-kembang dan tidur bayi di Kabupaten Klaten.

\section{METODE PENELITIAN}

Penelitian tergolong kuantitatif dengan rancangan quasi experiment with control group design. Digunakan dua kelompok yakni kelompok perlakuan (diberikan pijat bayi) dan kelompok kontrol (tidak dilakukan pijat bayi). Ibu ibu yang sudah dilatih diminta melakukan pijat bayi setiap minggu selama 1 bulan, sedangkan pada kelompok kontrol tak melakukan pijat.

Penelitian dilakukan di Kabupaten Klaten, antara bulan April hingga September 2019. Populasi dalam penelitian ini adalah bayi umur 3-9 yang dilakukan pengambilan sampel dengan area sampling sebanyak 57 bayi beserta ibunya di wilayah Puskesmas Trucuk dan Klaten Tengah.

Pengumpulan data meliputi berat badan menggunakan timbangan bayi dan panjang badan dengan mikrotois yang sudah dikalibrasi, sedangkan kuesioner untuk mengukur kualitas tidur pada kelompok eksperimen yang dilakukan oleh peneliti dan ditulis dalam lembar observasi, perlakuan pada kelompok eksperimen dilakukan pijat setiap minggu dalam kurun waktu 4 minggu dan ditimbang dipemijatan akhir. Pengumpulan data perkembangan motorik kasar dan halus bayi dilakukan dengan Kuesioner Pra Skrining Perkembangan (KPSP) yang sudah terstandarisasi oleh Kementerian Kesehatan RI pada awal periode pemijatan dan akhir pemijatan.

Pengambilan data dilakukan sebelum eksperimen disebut pretest dan sesudah eksperimen disebut post test begitu pula selama perlakuan diobservasi tumbuh-kembang dan kualitas tidurnya. Analisis pra dan post perlakuan dengan menggunakan Uji $t$ berpasangan sedangkan pada kelompok perlakukan dan kontrol dianalisis dengan menggunakan Uji t tidak berpasangan $(\alpha 0,05)$.

\section{HASIL PENELITIAN}

Hasil uji $t$ berpasangan menguji pengaruh sebelum dan sesudah pijat bayi 
dilakukan oleh ibu terhadap tumbuh- Klaten, disajikan pada tabel berikut ini: kembang dan tidur bayi di Kabupaten

Tabel 1. Berat Badan, Panjang Badan dan Perkembangan serta Kualitas Tidur sebelum dan sesudah dipijat pada Kelompok Perlakuan

\begin{tabular}{lccc}
\hline Variabel & Rerata Sebelum & Rerata Sesudah & T Hitung \\
\hline Berat badan & 6.625 & 7.602 & $-3.12(0.00)$ \\
Panjang badan & 6.297 & 67.95 & $-3.19(0.00)$ \\
Perkembangan & 7.27 & 9.25 & $-13.19(0.00)$ \\
Kualitas tidur & & & \\
Lama tidur sehari & 8.65 & 13.75 & $-26.54(0.00)$ \\
Lama tidur malam hari & 8.65 & 9.02 & $-2.42(0.02)$ \\
Frekuensi terbangun malam & 3.00 & 2.60 & $2,81(0.01)$ \\
Lama terbangun malam & 45.12 & 35.00 & $2.57(0.01)$ \\
\hline
\end{tabular}

Tabel 2. Berat Badan, Panjang Badan dan Perkembangan serta Kualitas Tidur sebelum dan sesudah dipijat pada Kelompok Kontrol

\begin{tabular}{lccc}
\hline Variabel & $\begin{array}{c}\text { Rerata } \\
\text { Sebelum }\end{array}$ & $\begin{array}{c}\text { Rerata } \\
\text { Sesudah }\end{array}$ & T Hitung-p value \\
\hline Berat badan & 7.294 & 7.335 & $-2.75(0,01)$ \\
Panjang badan & 63.53 & 63.76 & $-2.22(0,04)$ \\
Perkembangan & 8.65 & 9,35 & $-1.95(0,07)$ \\
Kualitas tidur & & & \\
Lama tidur sehari & 13.12 & 12.94 & $1.85(0.08)$ \\
Lama Tidur malam & 9,06 & 9,29 & $-1.82(0,09)$ \\
Frekuensi terbangun malam & 2,88 & 1.35 & $6.68(0,00)$ \\
Lama terbangun malam & 25.88 & 24.12 & $1.46(0,16)$ \\
\hline
\end{tabular}

Uji beda antara sebelum dan sesudah pijat bayi dilakukan oleh ibu terhadap tumbuh-kembang dan tidur bayi di Kabupaten Klaten diketahui pada kelompok perlakuan seluruhnya dengan hasil $\mathrm{p}<0,05$, sedangkan kelompok kontrol pada perkembangan, lama tidur dan lama terbangun $\mathrm{p}>0,05$, walaupun pada berat badan, panjang badan dan frekuensi terbangun $\mathrm{p}<0,05$.
Hasil tersebut menunjukkan terdapat pengaruh sebelum dan sesudah pijat bayi dilakukan oleh ibu terhadap tumbuhkembang dan tidur bayi di Kabupaten Klaten. Perbedaan antara kelompok perlakuan dengan kontrol tentang pijat bayi dilakukan oleh ibu terhadap tumbuhkembang dan tidur bayi di Kabupaten Klaten didapatkan hasil seperti pada tabel berikut:

Tabel 3. Uji Beda Tumbuh-Kembang dan Tidur Bayi antara Kelompok Perlakuan dan Kontrol.

\begin{tabular}{lccc}
\hline Variabel & Perlakuan-Kontrol & T Hitung & $\boldsymbol{p}$-value \\
\hline \multirow{2}{*}{ Berat badan } & 40 & 4,72 & 0,00 \\
\hline
\end{tabular}




\begin{tabular}{llll}
\hline Panjang badan & 40 & 2,55 & 0,01 \\
\hline Perkembangan & 17 & 3,87 & 0,00 \\
\hline Kualitas tidur & 40 & & \\
\hline Lama tidur sehari & 40 & 37.91 & 0.00 \\
\hline Lama Tidur malam & 17 & 30,77 & 0,00 \\
\hline Frekuensi terbangun & 40 & 10,46 & 0,00 \\
\hline Lama terbangun & 40 & 7,37 & 0,00 \\
\hline
\end{tabular}

Berdasarkan hasil uji $\mathrm{t}$ tidak berpasangan semua variabel menunjukkan $\mathrm{p}<0,05$, maka dapat dikatakan terdapat perbedaan pengaruh pijat bayi dilakukan oleh ibu terhadap tumbuh-kembang dan tidur bayi di Kabupaten Klaten antara kelompok perlakuan dan kontrol.

\section{PEMBAHASAN}

Pertumbuhan bayi yang diukur dari berat badan yang mendapatkan perlakuan pijat bayi dengan yang tidak mendapatkan perlakuan pijat bayi didapatkan rerata berat badan bayi pada kelompok perlakuan sebelum pemijatan 6.625 gram dan sesudah dipijat sebanyak 7.602 gram. Sedangkan pada kelompok kontrol sebelum pemijatan 7.294 gram dan sesudah pemijatan 7.335 gram. Kenaikkan rerata berat badan bayi yang mendapatkan perlakuan pijat sebesar 977 gram, sedangkan bayi yang tidak mendapatkan perlakuan pijat rerata kenaikannya hanya 41 gram. Melihat rerata berat badan bayi tersebut menunjukkan bahwa kelompok perlakuan mengalami peningkatan berat badan jauh lebih banyak. Peningkatan tonus saraf vagus (nervus cranial $x$ ) yang menyebabkan bertambahnya konsentrasi enzim penyerapan gastrin dan insulin dapat dirangsang melalui pijat, dengan demikian penyerapan makanan menjadi lebih baik (Roesli, 2016).

Penelitian serupa dilakukan oleh Jin Jing, et al (2007), dengan judul "Pijat dan Latihan Gerak Untuk Pertumbuhan dan Perkembangan Bayi" yang menyatakan pemberian pijatan dan latihan gerak dapat meningkatkan pertumbuhan fisik dan kecerdasan bayi mulai dari bayi lahir dengan $p=0,010$ untuk index berat badan.

Pijat bayi akan merangsang sekresi serotonin yang mempengaruhi pertumbuhan tulang pada bayi sehingga menmbah panjang badan. Serotonin yang berada di hipotalamus akan terangsang sekresinya sehingga mempengaruhi sekresi hormone pertumbuhan dengan hasil akhir adalah perpanjangan tulang jika bayi dilakukan pijat (Rosalina, dalam Sari dewi, 2016).

Perkembangan bayi yang diukur melalui Kuesioner Pra Skrining Perkembangan (KPSP) pada kelompok perlakuan sebelum dilakukan pemberdayaan pijat bayi pada ibu terhadap perkembangan didapatkan rerata skor KPSP sebesar 7.27 dan sesudah pijat 9.25. Sedangkan pada kelompok kontrol 
sebelum pijat sebesar 8.65 dan sesudah pijat 9.35. Perbedaan rerata kenaikan nilai KPSP yang mendapatkan perlakuan pijat bayi jauh lebih besar yakni 1.98 dibanding yang tidak dipijat (kontrol) hanya 0.7, hal itu menunjukkan laju perkembangan anak yang dipijat dapat meningkat dari perkembangan anak meragukan (M) ke perkembangan anak sesuai tahapan perkembangan (S) sedangkan pada kontrol tidak terjadi percepatan perkembangan.

Suplai oksigen yang terlarut dalam sirkulasi darah akan lebih maksimal ke jaringan pada bayi yang mengalami stimulasi pijat, sehingga dapat meningkatkan perkembangan otot dan pertumbuhan sel (Chamida, 2009). Pijat bayi merupakan salah satu jenis stimulasi taktil. Stimulasi taktil adalah suatu jenis rangsangan sensori yang paling penting untuk perkembangan bayi yang optimal.

Lama tidur bayi dalam sehari diukur dari banyaknya tidur bayi baik malam maupun siang hari untuk bayi yang mendapatkan perlakuan pijat bayi dengan yang tidak mendapatkan perlakuan pijat bayi didapatkan rerata lama tidur bayi dalam sehari pada kelompok perlakuan sebelum pijat sebanyak 8.65 jam dan sesudah pijat sebanyak 13.75 jam, sedangkan pada kontrol malah berkurang lama tidurnya dari 13.12 jam menjadi 12.94 jam.

Lama tidur bayi pada malam hari diukur dari banyaknya tidur bayi yang terjadi di malam hari, untuk bayi yang mendapatkan perlakuan sebelum pijat sebanyak 8,65 jam dan sesudah pijat sebanyak 9,02 jam, sedang pada kontrol hamper tidak terjadi perubahan dari sebelumnya 9.06 dan sesudahnya 9.29 jam. Frekuensi terbangun malam hari pada tidur bayi diukur dari banyaknya tidur bayi terbangun saat tidur yang terjadi di malam hari. Frekuensi terbangun tidur bayi pada malam hari pada kelompok perlakuan sebelum pijat sebanyak 3 kali dan sesudah pijat sebanyak 2,6 kali. Sedangkan pada kelompok kontrol sebelumnya 2,88 kali dan sesudahnya 1,35 kali.

Lama terbangun di malam hari diukur dari lamanya terjaga bayi untuk tidur lagi. Bayi yang mendapatkan perlakuan pijat dari 45.12 menit menjadi 35 menit sedangkan pada kontrol sebelumnya 25.88 menit dan sesudahnya 24.12 menit. Menurut Roesli (2016), bayi yang dipijat akan tertidur lebih lelap, sedangkan pada waktu bangun konsentrasinya akan lebih penuh. Kualitas tidur yang baik ditunjukkan dengan jumlah jam tidur bayi yang cukup, bayi dapat jatuh tertidur dengan mudah di malam hari, bugar saat bangun tidur, dan tidak rewel.

Hasil penelitian mendukung penelitian yang dilakukan oleh Prof. T. Field dan Scafidi (1986 dan 1990) dalam Rusli (2016) bahwa pada 20 bayi premature yang dipijat $3 \times 10$ menit dalam 10 hari mengalami kenaikan berat badan perhari $20 \%$ - 47\% lebih banyak dari yang tidak dipijat. Penelitian pada bayi cukup bulan yang berusia $1-3$ bulan, dipijat 15 menit, $2 \times$ seminggu selama 6 minggu didapatkan kenaikan berat badan yang lebih dari kontrol.

\section{KESIMPULAN DAN SARAN}

Tumbuh-kembang dan tidur bayi antara sebelum dan sesudah bayi dilakukan pijat oleh ibunya didapatkan hasil dengan $\mathrm{p}<0,05$ dan pada bayi yang dipijat oleh ibunya dibandingkan dengan bayi yang tidak dipijat didapatkan hasil dengan $\mathrm{p}<0,05$. Sehingga dapat disimpulkan terdapat pengaruh pijat bayi 
yang dilakukan oleh ibu terhadap tumbuhkembang dan tidur bayi di Kabupaten Klaten. Peneliti merekomendasikan pijat bayi untuk meningkatkan kemampuan motorik anak serta meningkatkan kualitas tidur anak.

\section{DAFTAR RUJUKAN}

Chamidah. (2009). Deteksi Dini Gangguan Pertumbuhan dan Perkembangan Anak, Jurnal Pendidikan Khusus, Volume 4 No: 3, UNY Yogyakarta.

Dinas Kesehatan Kabupaten Klaten. (2018). Profil Kesehatan Tahun 2018, Jl Pemuda 313 Klaten.

Jing, Jin et al. (2007). Massage and Motion Training For Growth and Development of Infants. Guangzhou : World J Pediatric.

Kementerian Kesehatan Republik Indonesia. (2016). Buku Ajar Kesehatan Ibu dan Anak. Pusat Pendidikan dan Pelatihan tenaga Kesehatan. Jakarta.

Sari Dewi. (2016). Pengaruh Pemijatan terhadap Pertumbuhan dan Perkembangan Bayi Umur $3-4$ Bulan di Wilayah Kerja Puskesmas Kanjilo Kecamatan Barombong Kabupaten Gowa. Umi Medical Jurnal, Volume 1 Nomer 1 (2016).

Shelov. (2005). Caring for your Baby and Young Chlid: Birth to age 5, American Academic Pediatrics.

Soetjiningsih. (2014). Tumbuh Kembang Anak, Jakarta, EGC
Sunartyo. (2005). Panduan Merawat Bayi dan Balita agar Tumbuh Sehat dan Cerdas. Diva Press. Yogyakarta.

Susilaningrum, Nursalam dan Utama. (2013). Asuhan Keperawatan Bayi dan Anak untuk Perawat dan Bidan. Salemba Medika. Jakarta.

Roesli. (2016). Pedoman Pijat Bayi. Trubus Agriwidya. Jakarta. 